this case and I am much indebted to Mr. H. L. Barnard for demonstrating the exact conditions present.

\section{A NOTE ON A CASE OF SUPPURATIVE PAROTITIS IN AN INFANT.}

By P. Maynard Heath, M.S. Lond., F.R.C.S. Eng., ASSISTANT SURGEON TO THE EVELINA HOSPITAL FOR SICK CHILDREN, SOUTHWARK.

THE patient, aged three months, was sent to the Evelina Hospital by Mr. W. A. Montgomery, of Worcester Park, who gave me the following history. "Three weeks ago the baby was fretful and feverish, with slight convulsions. The temperature was $101.6^{\circ} \mathrm{F}$. A squint developed and the head was retracted with marked rigidity of the posterior cervical muscles. There was no vomiting, nor has there been any since. Under the influence of sodium bromide the child was induced to sleep. On the third day there was marked Cheyne-Stokes respiration which lasted 24 hours. The symptoms gradually subsided, but two days ago the child developed a considerable swelling below and behind the left ear and showed evident signs of being in pain."

When seen by me the swelling corresponded in position to the left parotid gland. The skin over it was slightly cedematous but there was no fluctuation. The head was drawn backwards and to the left, with marked rigidity of the neck muscles on the left side. There were no signs of intracranial disease, and the temperature was $99 \cdot 2^{\circ}$. The cavity of the mouth appeared to be clean, but on making pressure over the parotid swelling a bead of pus appeared at the orifice of Stenson's duct. A pure culture of staphylococcus pyogenes citreus was afterwards obtained from the pus. The mother was instructed to apply fomentations to the swelling and to cleanse the mouth with an antiseptic lotion. By the following week the condition had completely cleared up and the child's temperature was normal. The child was breast fed and was otherwise healthy. There was no disease of the mother's nipple. The source of infection was apparently an exceedingly dirty "comforter" which, as Mr. Montgomery remarked, would probably have yielded micrococci of all the known colours and formations.

Devonshire-street, $\mathrm{W}$.

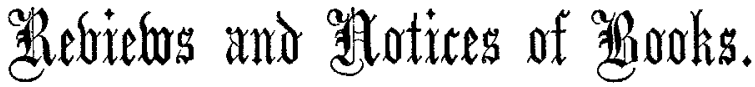

Studies from the Rockefeller Institute for Medical Researoh. Vol. VI. 1907.

IN $1901 \mathrm{Mr}$. Rockefeller founded the Rockefeller Institute for Medical Research, guaranteeing a sum of $\$ 200,000$ for the first ten years. The board of directors of the institute decided to commence by creating a number of scholarships to be distributed amongst the existing laboratories in the United States. In this way it was hoped that several ends might be attained : first, the enlisting of the coöperation of various investigators in different places; secondly, the assisting of some promising lines of research which could not be continued for lack of funds; and, lastly, the discovery of who and where were the persons who desired to undertake research work and what were their qualifications. 23 grants were made to 18 different laboratories and three men were sent abroad to pursue special investigations, two in Ehrlich's laboratory in Frankfort and one in Koch's Institute in Berlin. After a year's trial it was decided to form a laboratory with its own staff of workers, and the founder gave a larger gift to enable the directors to acquire land and to build a laboratory, but meanwhile a building was found that served as a temporary laboratory. Dr. Simon Flexner was appointed chief director, and 18 months were spent in finding a suitable site and in drawing up plans for the new building, and five of the directors of the institute visited Europe to examine similar institutions. As to the staff, with each year's experience the conviction has steadily grown that the institute must to a large extent train its own staff, and to get in touch with the class from which the members of the staff could be chosen a number of resident scholarships were created. The work done by, and under the auspices of, the institute has been collected in volumes of reprints, and the sixth volume lies before us and from it we have taken this account. In 1905 the institute obtained control of the Journal of Experimental Medicine and that serves as a special organ of publication. The new building was completed in 1906 and it seems admirably fitted for the work of the institute. It has been built and fitted up with the most elaborate and suitable apparatus and the expense has been considered of secondary importance.

This sixth volume of reports contains some 40 papers, and though none of them can be considered as epoch-marking, yet each contains some proof of progress in experimental medicine. The first paper is devoted to a study of the spirillum of relapsing fever, by Professor F. G. Novy and Mr. R. E. Knapp. They conclude that this spirillum is not protozoal in nature but really bacterial. They show that during the stage of decline a germicidal body and an immunising body are present in the blood and infected rats and monkeys can be promptly cured by injecting hyper-immunised blood.

Dr. Richard M. Pearce has studied the attempts at repair made by livers which had been damaged by the injection of hæmagglutinative sera. The first sign of repair is the occurrence of mitotic figures in the liver cells after 38 hours. Then the endothelial cells proliferate and a granulation tissue forms, replacing the necrotic areas. Later, the proliferated liver cells largely replace the new connective tissue. New bile-ducts form and some of their epithelium is converted into liver cells.

Dr. S. J. Meltzer and Dr. John Auer have reported experiments in which the action of magnesium salts has been investigated and they find that the salts have no irritating effect even when employed in strong solution; that they cause a more or less complete block both for afferent and efferent impulses, and that this effect is produced whatever the concentration of the solution. They have also studied the subcutaneous and intravenous injection of magnesium salts, and they maintain, in opposition to MacCallum, that by neither method of injection is purgation or intestinal peristalsis produced. In fact, the injection of magnesium salts inhibits some forms of intestinal peristalsis.

Dr. Wilfred H. Manwaring has a useful paper in which he shows that all attempts to apply physical chemistry to serum pathology have as their foundation the assumption that the effect of certain solutions is a direct measure of the amount of a certain free or bound component in those solutions, but the assumption rests on no experimental grounds and cannot be verified until we can isolate toxins, antitoxins, and other such bodies. Thus it follows that measurements so far made in serum pathology are practically only of historic interest to the physical chemist.

Dr. Meltzer and Dr. Auer have investigated the action of ergot on the stomach and intestines and they have found that it increases the spontaneous movements and augments the motor effect of the vagus, but atropine greatly reduced the effect of the ergot. The action of alcohol on the secretion of bile has been studied by Dr. W. Salant and the experiment showed that it had no effect on the amount of bile secreted. Dr. Martha Wollstein investigated the question of the presence of influenza bacilli in the throat and bronchial mucus of children and she found that the bacillus does not occur in the throats of healthy children but that it persists long after recovery from influenza; Dr. Wollstein considers that the term "pseudo-influenza bacillus" should be discarded.

A valuable paper is that by Dr. Meltzer and Dr. Auer 